\title{
In vitro biological activities of clove essential oil formulations against Microsporum gallinae ATCC 90749
}

\author{
Jareerat Aiemsaard $^{\mathrm{a}, \mathrm{b}, *}$, Chuchat Kamollerd ${ }^{\mathrm{a}}$, Prawit Butudom ${ }^{\mathrm{a}}$, Kanlaya Worawong ${ }^{\mathrm{a}}$, \\ Eakachai Thongkham $^{\mathrm{a}}$ \\ a Faculty of Veterinary Medicine, Khon Kaen University, Khon Kaen 40002 Thailand \\ b Biofilm Research Group, Khon Kaen University, Khon Kaen 40002 Thailand
}

*Corresponding author, e-mail: jaraim@kku.ac.th

Received 10 Feb 2020

Accepted 11 Jul 2020

\begin{abstract}
Avian dermatophytosis is a disease caused by Microsporum gallinae. The disease can cause economic loss in farmed chickens. We investigated the antifungal activity of clove essential oil (CO) against M. gallinae ATCC 90749. The main components of CO were identified by GC-MS, eugenol (98.87\%) and trans-caryophyllene (1.13\%) were found. The antioxidant activity of CO was determined by DPPH assay, the antioxidation index (AI) ranged from $86.55 \pm 0.77$ to $92.37 \pm 0.25 \%$, which was significantly higher than vitamin E and BHT $(p<0.05)$. The antifungal activity was determined by broth microdilution method and time-kill kinetics assay. The minimum inhibitory concentration (MIC) and the minimum fungicidal concentration (MFC) of CO against M. gallinae were 0.005 and $0.01 \% \mathrm{v} / \mathrm{v}$, respectively. Time-kill assay showed that the antifungal activity of CO was dose and time-dependent. The time taken to reduce the number of viable $M$. gallinae by more than $99.99 \%$ was $15 \mathrm{~min}$ and $3 \mathrm{~h}$ for 2 and $1 \% \mathrm{v} / \mathrm{v}$ CO, respectively. Ointments and cream formulations containing CO were tested for antifungal activity using time-kill kinetics assay. Both the 2 and $4 \% \mathrm{w} / \mathrm{w}$ formulations of the CO ointments and creams reduced the number of viable M. gallinae by more than $99.999 \%$ within $15 \mathrm{~min}$. The results of this study show that $\mathrm{CO}$ has the potential to be developed as a drug for treating fungal skin diseases in poultry. Further studies on the stability and efficacy of these $\mathrm{CO}$ formulations in vivo are needed.
\end{abstract}

KEYWORDS: clove essential oil, antioxidant, anti-M. gallinae, time-kill assay, ointment and cream formulations

\section{INTRODUCTION}

Microsporum gallinae is a fungus of the genus $\mathrm{Mi}$ crosporum that causes avian dermatophytosis or favus. Avian dermatophytosis is a sporadic disease found throughout the world in chickens, fighting cocks and poultry farms [1]. Lesions appear on the head, wattles, and neck and have white crusts, hyperkeratosis and may include feather loss. It causes the animals distress and affects economic output by decreasing the carcass quality of the animals in the slaughterhouse [2]. Hubalek [3] reported that the prevalence of fungal skin diseases in chickens was $2.6 \%$. Nweze [4] found the prevalence of fungal skin diseases was $18.2 \%$ in chickens and $13.6 \%$ in ducks, with $M$. gallinae isolated from $75 \%$ of infected chickens and 100\% of infected ducks. M. gallinae has also been reported to infect dogs, monkeys, cats, squirrels, mice, canaries, pigeons, and turkeys, as well as causing ringworm in humans, and severe infections in immunocompromised hosts $[5,6]$.

The current treatment for avian dermatophyto- sis uses antifungal drugs such as miconazole and tolnaftate creams, while pentachlorophenol and 5bromosalicyl-4-chloranilide are used as a dip [7]. These drugs can cause adverse drug effects such as irritation, redness, and itching of the skin and can be toxic to the liver, kidneys, circulatory system and nervous system. If used at high concentrations, they may be harmful to users and animals. In addition, drug use must be discontinued in livestock animals to allow for the withdrawal of drugs before sending to the slaughterhouse [8]. Therefore, there are many studies investigating natural substances as alternative antifungal drugs.

Cloves are the dried aromatic flower buds of a tree in the family Myrtaceae (Syzygium aromaticum (L.) Merr. \& L.M. Perry) and are used in traditional medicine as an anti-inflammatory, cough suppressant, local anaesthetic, and to reduce toothache and relieve colic. In addition, cloves have antioxidant activity, and are highly effective against bacteria, fungi, and viruses. The constituents of clove es- 
sential oil are mainly eugenol, eugenol acetate, and $\beta$-caryophyllene [9]. A review of the literature indicated that clove essential oil has good antifungal activity against Microsporum canis, Microsporum gypseum, Trichophyton rubrum, Trichophyton mentagrophytes, and Epidermophyton floccosum $[10,11]$. However, information about the antifungal activity of clove essential oil against $M$. gallinae is limited. Therefore, we investigated the in vitro efficacy of clove essential oil against $M$. gallinae causing avian dermatophytosis.

\section{MATERIALS AND METHODS}

\section{Materials}

M. gallinae ATCC 90749 was obtained from the American Type Culture Collection (ATCC), Virginia, USA. Clove essential oil was purchased from ThaiChina Flavors and Fragrances Industry Co., Ltd., Ayutthaya, Thailand, batch no. 6010334-1. The essential oil was extracted from flower buds of S. aromaticum (L.) Merr. \& L.M. Perry) by steam distillation. Ketoconazole and clotrimazole were from Sigma-Aldrich, Germany. Other chemicals were purchased from: dimethyl sulfoxide (DMSO) from V.S. Chem House, Ayutthaya, Thailand; absolute ethanol and hexane from Merck, Germany; tocopheryl acetate (vitamin E) from Namsiang Co., Ltd., Bangkok, Thailand; butylated hydroxytoluene (BHT) from Riedel de Haen, Lower Saxony, Germany; 2,2-diphenyl-1-1-picrylhydrazil (DPPH) from Fluka, Germany; Sabouraud dextrose agar (SDA) and Sabouraud dextrose broth (SDB) from Becton Dickinson, Grenoble, France. All of ingredients of the ointment and cream formulations were obtained from the Chemipan Corporation Co., Ltd., Bangkok, Thailand.

\section{Determination of chemical composition by gas chromatography-mass spectrometry (GC-MS) analysis}

The GC-MS analysis was performed according to the method previously described by Aiemsaard et al [12] and Amelia et al [13] with modifications for the Agilent CN10402086 gas chromatograph (separating vaporized mixtures instrument) interfaced with the Agilent US35120381 mass spectrometer (detector). The column used was a DB$5 \mathrm{~ms}$ fused silica capillary column $(30 \mathrm{~m} \times 25 \mathrm{~mm}$, film thickness $0.25 \mu \mathrm{m}$ ). The carrier gas was helium with a flow rate of $1 \mathrm{ml} / \mathrm{min}$. The oven temperature was increased from $70-120^{\circ} \mathrm{C}$ at a rate of $3^{\circ} \mathrm{C} / \mathrm{min}$, then from $120-270^{\circ} \mathrm{C}$ at $5^{\circ} \mathrm{C} / \mathrm{min}$. The chemical constituents of clove essential oil were identified by comparing the results of the chromatogram and reference retention times.

\section{Determination of antioxidant activity by DPPH assay}

The DPPH assay was performed according to the method previously described by Lertsatitthanakorn et al [14]. Briefly, clove essential oil was diluted with DMSO to give a final concentration of $16 \% \mathrm{v} / \mathrm{v}$ and $50 \mu \mathrm{l}$ was added to $50 \mu \mathrm{l}$ of absolute ethanol in 96-well round-bottomed microtiter plates (Corning Incorporated, USA). Serial two-fold dilutions were done. Then $50 \mu$ l of $0.0004 \mathrm{M} \mathrm{DPPH}$ solution was added into all test wells and mixed for $5 \mathrm{~min}$. The mixtures were incubated in the dark for $25 \mathrm{~min}$ at room temperature and their absorbance at $517 \mathrm{~nm}$ was recorded by Vis-spectrophotometer (Genesys 10 VIS, Thermo Scientific, USA). BHT and vitamin $\mathrm{E}$ were used as positive antioxidant controls. The percentage of DPPH radical inhibition (\% antioxidation index; \%AI) was calculated according to the following equation:

$$
\% \mathrm{AI}=\frac{\mathrm{Abs}_{\mathrm{ct}}-\left(\mathrm{Abs}_{\mathrm{s}}-\mathrm{Abs}_{\mathrm{b}}\right)}{\mathrm{Abs}_{\mathrm{ct}}} \times 100,
$$

where $\mathrm{Abs}_{\mathrm{ct}}$ represents the absorbance of the sample containing all reagents except the antioxidant, $\mathrm{Abs}_{\mathrm{s}}$ is the absorbance of the sample containing an antioxidant, and $\mathrm{Abs}_{\mathrm{b}}$ is the absorbance of the sample containing all reagents except antioxidant and DPPH.

\section{Determination of antifungal activity by broth microdilution method}

The MICs and MFCs of clove essential oil were determined by the broth microdilution method according to Chamdit et al [15] with modification. Briefly, $50 \mu \mathrm{l}$ of SDB was added to all wells of a 96-well round-bottomed microtiter plate. Clove essential oil was diluted with DMSO to give a final concentration of $5 \%$ and added to each well of the first column. Serial two-fold dilutions were done from the first to the tenth columns. Fifty microliters of M. gallinae suspension $\left(10^{4}-10^{5} \mathrm{CFU} / \mathrm{ml}\right)$ was added into wells from the first to eleventh columns. The wells of the eleventh and twelfth columns were used as positive and negative growth controls. The plate was incubated at room temperature $\left(25-30^{\circ} \mathrm{C}\right)$ for 72-96 h. Ketoconazole and clotrimazole were used as antifungal controls. DMSO was used as solvent control. The MIC was determined from the lowest 
Table 1 Ingredient of ointment and cream formulations (100 g).

\begin{tabular}{lllr}
\hline Formulation & Phase & Ingredient & Amount $(\mathrm{g})$ \\
\hline \multirow{4}{*}{ Ointment } & \multirow{2}{*}{ Oil } & Stearyl alcohol & 25 \\
& & White soft paraffin & 25 \\
\cline { 2 - 4 } & & Sodium lauryl sulfate & 1 \\
& \multirow{2}{*}{ Water } & Propylene glycol & 12 \\
& & Methylparaben & 0.025 \\
& & Propylparaben & 0.015 \\
& & Distilled water & Add to 100 \\
\hline \multirow{5}{*}{ Cream } & & Mineral oil & 10 \\
& \multirow{2}{*}{ Oil } & White beeswax & 5 \\
& & Cetyl alcohol & 5 \\
& & Span 60 & 2.5 \\
\cline { 2 - 4 } & Water & Tween 60 & 7.5 \\
\hline
\end{tabular}

concentration of antifungal agent inhibiting visible growth after 72-96 h of incubation. Ten microliters from the wells with no visible growth was inoculated onto SDA plates and incubated at room temperature for 72-96 h. The MFC was determined from the lowest concentration of antifungal agent that inhibited growth on SDA. All tests were performed in eight duplicates.

\section{Determination of antifungal activity by time-kill kinetics assay}

The antifungal activity of clove essential oil was studied according to Chamdit et al [15] with modifications. Briefly, $100 \mu \mathrm{l}$ of $M$. gallinae suspension $\left(10^{4}-10^{5} \mathrm{CFU} / \mathrm{ml}\right)$ was mixed with clove essential oil and diluents in microcentrifuge tubes $(1.5 \mathrm{ml})$ to give final concentrations of 10, 100, 200 and 400 times of MIC in $1000 \mu \mathrm{l}$, then mixed by vortex mixer for $1 \mathrm{~min}$. After incubation for 15 and $30 \mathrm{~min}$, 3,6 and $24 \mathrm{~h}$ at room temperature, $100 \mu \mathrm{l}$ from each microcentrifuge tube was inoculated onto SDA. Each experiment was performed in triplicate.

\section{Formulation preparation, and antifungal activity evaluation}

Clove essential oil was prepared as two formulations: ointment and cream. The composition and amounts of the formulation ingredients are shown in Table 1. Both the oil phase and water phase were separately heated up to $75-80^{\circ} \mathrm{C}$. Then, the water phase was added to the oil phase with continuous stirring. The appropriate amount of clove essential oil was added to give final concentrations of $2 \%$ and $4 \% \mathrm{v} / \mathrm{w}$, and then stirring continued until ointment and cream were formed. The antifungal activity
Table 2 Chemical composition of $S$. aromaticum (clove essential oil) as determined by GC-MS.

\begin{tabular}{lccr}
\hline Component & $\begin{array}{c}\text { Molecular } \\
\text { formula }\end{array}$ & $\begin{array}{c}\text { Retention } \\
\text { time (min) }\end{array}$ & $\begin{array}{r}\text { Area } \\
(\%)\end{array}$ \\
\hline Eugenol & $\mathrm{C}_{10} \mathrm{H}_{12} \mathrm{O}_{2}$ & 23.37 & 98.87 \\
Trans-caryophyllene & $\mathrm{C}_{15} \mathrm{H}_{24}$ & 26.35 & 1.13 \\
\hline
\end{tabular}

was performed by the time-kill kinetics assay as described above.

\section{Statistical analysis}

Each experiment was performed in either triplicate or eight duplicates and the data were reported as mean \pm standard deviation. One-way ANOVA was used to compare means ( $\alpha=0.05$ ). All analyses were performed using SPSS for Windows version 19.0 (SPSS Inc., USA), KKU license.

\section{RESULTS AND DISCUSSION}

\section{Chemical composition and antioxidant activity of clove essential oil}

GC-MS analysis showed that the tested CO consisted of 2 main constituents: eugenol, which had the highest concentration (98.87\%), and trans-caryophyllene with a concentration of $1.13 \%$ (Table 2). This result was in accordance with the previous studies of Pumnuan et al [16], which showed $97.1 \%$ eugenol and $1.685 \%$ transcaryophyllene, and Asawapattanakul et al [17], which showed the concentration of eugenol and trans-caryophyllene as $98.87 \%$ and $1.13 \%$, respectively. The results of multiple studies have shown the main constituents of $\mathrm{CO}$ are more than $70 \%$ eugenol, followed by $5-15 \%$ of eugenyl acetate and $\beta$-caryophyllene [18-20]. Differences in the chemical composition of CO depend on the environment and geography of the cultivated area, plant part used, as well as the storage conditions and extraction methods used [21, 22].

The antioxidant activities of the tested $\mathrm{CO}$, as determined by DPPH assay, are shown in Table 3. All concentrations of CO $(0.125-8 \%)$ had a strong antioxidant effect (range 86.55-92.37\%AI), which was higher than the \%AI of $1-8 \%$ BHT and all concentrations of vitamin $\mathrm{E}(p<0.05)$. Multiple previous studies have shown that $\mathrm{CO}$ has a high antioxidant capacity tested by DPPH assay [23, 24], which is consistent with the findings of our study. Hemalatha et al [22] reported that $0.02 \%$ CO had \%AI ranging from 85.3-92.2\%, which was greater than that for vitamin $\mathrm{E}(84.1 \% \mathrm{AI})$. Moreover, the 
Table 3 Antioxidation indices of tested concentrations (0.125-8\%) of clove essential oil (CO), vitamin E and butylated hydroxytoluene (BHT).

\begin{tabular}{lccccccc}
\hline Substance & \multicolumn{7}{c}{ Antioxidation index (\%) } \\
\cline { 2 - 7 } & $0.125 \%$ & $0.25 \%$ & $0.5 \%$ & $1 \%$ & $2 \%$ & $4 \%$ & $8 \%$ \\
\hline CO & $86.55 \pm 0.77^{\mathrm{a}}$ & $87.88 \pm 0.66^{\mathrm{a}}$ & $89.65 \pm 0.58^{\mathrm{a}}$ & $91.41 \pm 0.22^{\mathrm{a}}$ & $91.12 \pm 0.34^{\mathrm{a}}$ & $92.30 \pm 0.22^{\mathrm{a}}$ & $92.37 \pm 0.25^{\mathrm{a}}$ \\
Vitamin E & $20.25 \pm 0.43^{\mathrm{b}}$ & $32.84 \pm 2.17^{\mathrm{b}}$ & $48.95 \pm 1.91^{\mathrm{b}}$ & $62.50 \pm 1.80^{\mathrm{c}}$ & $88.58 \pm 0.43^{\mathrm{b}}$ & $89.07 \pm 0.32^{\mathrm{b}}$ & $89.41 \pm 0.12^{\mathrm{b}}$ \\
BHT & $87.76 \pm 1.24^{\mathrm{a}}$ & $88.38 \pm 0.83^{\mathrm{a}}$ & $89.69 \pm 1.06^{\mathrm{a}}$ & $87.97 \pm 0.83^{\mathrm{b}}$ & $88.24 \pm 0.48^{\mathrm{b}}$ & $88.10 \pm 0.72^{\mathrm{b}}$ & $88.10 \pm 0.55^{\mathrm{b}}$ \\
\hline
\end{tabular}

Values represent the means of triplicate experiments \pm SD. Different superscript letters within a column indicate statistically significant differences between the means $(p<0.05)$.

result of Nassar et al [25] showed 83\%AI for 0.04\% $\mathrm{CO}$, which was similar to BHT.

The antioxidant effect of $\mathrm{CO}$ is presumably due to the main component eugenol, which belongs to the group of phenolic volatile oils. Further antioxidant effects may come from other phenolic compounds such as eugenyl acetate, flavonoids, hydroxybenzoic acids, hydroxycinnamic acids, hydroxyphenylpropenes, and others [26]. Eugenol has radical scavenging and metal ion chelating properties, acting as a reducing agent, hydrogen atom donator and singlet oxygen scavenger. When the hydrogen atom from the phenolic hydroxyl group is given to the DPPH phenoxyl radical (DPPH.), the radical is changed to its reduced form (DPPH-H), leading to increased stability and stopping the chain reaction of oxidation $[27,28]$. Excessive production of reactive oxygen species is called oxidative stress, which is commonly found in inflamed tissues due to infection, allergies, poisoning, and autoimmune diseases. Excessive release of proinflammatory cytokines during the immune response causes cell and tissue damage, and oxidative stress consequently follows. While inflammation is producing oxidative stress, the reactive oxygen species and other oxidative agents increase the severity of inflammation. For these reasons, inhibiting the chain reaction of oxidation can reduce the inflammatory process in affected tissues $[29,30]$.

\section{Antifungal activity of clove essential oil against M. gallinae ATCC 90749}

The antifungal activities of $\mathrm{CO}$ and two antifungal drugs, clotrimazole and ketoconazole, against M. gallinae ATCC 90749 are shown in Table 4. The $\mathrm{CO}$ and both antifungal drugs showed high effectiveness against $M$. gallinae. The MIC of CO $(0.005 \% \mathrm{v} / \mathrm{v})$ was 2 times lower than its MFC $(0.01 \% \mathrm{v} / \mathrm{v})$, while MICs of ketoconazole and clotrimazole $(0.000048$ and $0.000024 \% \mathrm{w} / \mathrm{v})$ were 4 and 83 times lower than their MFCs (0.0002 and
Table 4 Minimum inhibitory concentrations and minimum fungicidal concentrations of clove essential oil $(\% \mathrm{v} / \mathrm{v})$ and antifungal drugs (\% w/v) against $M$. gallinae ATCC $90749(n=8)$.

\begin{tabular}{lrr}
\hline Antifungal agent & \multicolumn{1}{c}{ MIC } & \multicolumn{1}{c}{ MFC } \\
\hline Clove essential oil & $0.005 \pm 0.00^{\mathrm{b}}$ & $0.01 \pm 0.00^{\mathrm{b}}$ \\
Clotrimazole & $0.000024 \pm 0.00^{\mathrm{d}}$ & $0.002 \pm 0.00^{\mathrm{c}}$ \\
Ketoconazole & $0.000048 \pm 0.00^{\mathrm{c}}$ & $0.0002 \pm 0.00^{\mathrm{d}}$ \\
\hline
\end{tabular}

Values represent the means of eight fungal samples \pm SD. Different superscript letters within a column indicate statistically significant differences between the means $(p<0.05)$.

$0.002 \% \mathrm{w} / \mathrm{v}$ ), respectively. Although ketoconazole and clotrimazole had higher antifungal efficacies than CO, CO provided good results in this study when compared to the disadvantages of antifungal drugs such as side effects, fungal-resistance, and high price. Although no previous study has reported activity of $\mathrm{CO}$ against $M$. gallinae, many studies have reported antifungal activity of $\mathrm{CO}$ against other Microsporum spp. and dermatophytes [31,32]. The report of Pinto et al [33] showed that CO had MICs and MFCs against $M$. canis and M. gypseum (standard strains) in the range of $0.00625-0.05 \% \mathrm{w} / \mathrm{v}$. Aiemsaard et al [34] reported MIC and MFC of $\mathrm{CO}$ against $M$. canis and T. mentagrophytes were $0.00002 \% \mathrm{v} / \mathrm{v}$ and $0.00004 \% \mathrm{v} / \mathrm{v}$, and the MIC and MFC against $M$. gypseum were $0.00004 \% \mathrm{v} / \mathrm{v}$. Our results for the standard antifungal drug activities against $M$. gallinae corresponded to the study of Fernandez-Torres et al [35] who reported ketoconazole and clotrimazole MICs for M. gallinae of 0.000025 and $0.000001 \% \mathrm{w} / \mathrm{v}$, respectively.

\section{Time kill assay of clove essential oil on M. gallinae ATCC 90749}

The time-kill kinetics of antifungal activity of CO against M. gallinae ATCC 90749 is given in Fig. 1. 


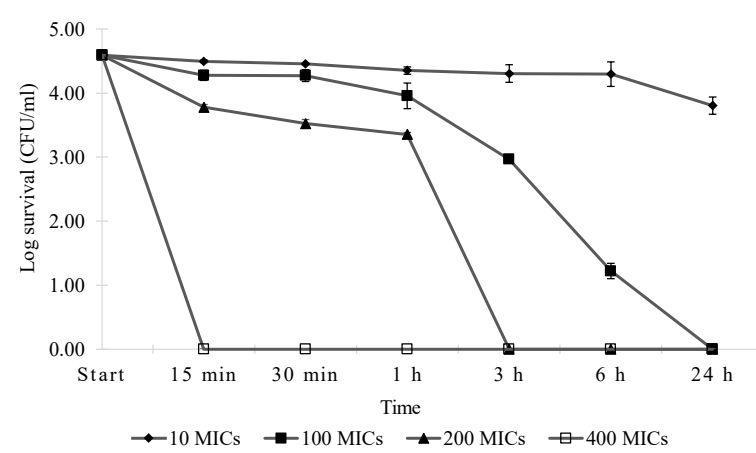

Fig. 1 The time-kill assay of clove essential oil against M. gallinae ATCC 90749. Values represent the means of triplicate experiments with error bars (SD). $10 \mathrm{MICs}=$ $0.05 \% \mathrm{v} / \mathrm{v}, 100 \mathrm{MICs}=0.5 \% \mathrm{v} / \mathrm{v}, 200 \mathrm{MICs}=1 \% \mathrm{v} / \mathrm{v}$, $400 \mathrm{MICs}=2 \% \mathrm{v} / \mathrm{v}$.

The results demonstrated that the effectiveness of $\mathrm{CO}$ is dose and time-dependent. The solution of $\mathrm{CO}$ at 400 times its MIC $(20 \mu \mathrm{l} / \mathrm{ml} ; 2 \% \mathrm{v} / \mathrm{v})$ possessed the most potent anti-M. gallinae effect, eradicating more than $99.99 \%$ (4-log reduction) of the inoculum within $15 \mathrm{~min}$. The second most effective concentration of CO was 200 times MIC $(10 \mu \mathrm{l} / \mathrm{ml}$; $1 \% \mathrm{v} / \mathrm{v}$ ), which gave a $90 \%$ reduction in viable fungi (1-log reduction) at $30 \mathrm{~min}$ and $1 \mathrm{~h}$, and more than $99.99 \%$ reduction at $3 \mathrm{~h}$. This was followed by 100 times MIC ( $5 \mu \mathrm{l} / \mathrm{ml} ; 0.5 \% \mathrm{v} / \mathrm{v})$, which required at least $3 \mathrm{~h}$ to reduce the number of viable fungi by $90 \%$, and at least 6-24 h for $99.99 \%$ reduction. The CO concentration at 10 times MIC $(0.5 \mu \mathrm{l} / \mathrm{ml}$; $0.05 \% \mathrm{v} / \mathrm{v})$ did not have any antifungal activity against $M$. gallinae up to $6 \mathrm{~h}$, but did reduce the number of fungi slightly after $24 \mathrm{~h}$. Previous studies have suggested that the antifungal effect of $\mathrm{CO}$ results from eugenol, the main constituent, which destroys the fungal cell wall and cell membrane, and causes deformation of molecules within the cells $[10,36]$.

\section{Antifungal activity of clove essential oil ointment and cream against $M$. gallinae ATCC 90749}

Based on the results of the time-kill kinetic experiments, ointments and creams containing 2 and $4 \% \mathrm{v} / \mathrm{w}$ CO were formulated. The time-kill assays of the formulations (Fig. 2) show that both 2 and 4\% $\mathrm{CO}$ formulations of ointment and cream decreased the number of viable fungal cells by more than 99.999\% (5-log reduction) within 15 min. These results indicated that the $\mathrm{CO}$ contained in both formulations retained its efficacy against $M$. gallinae

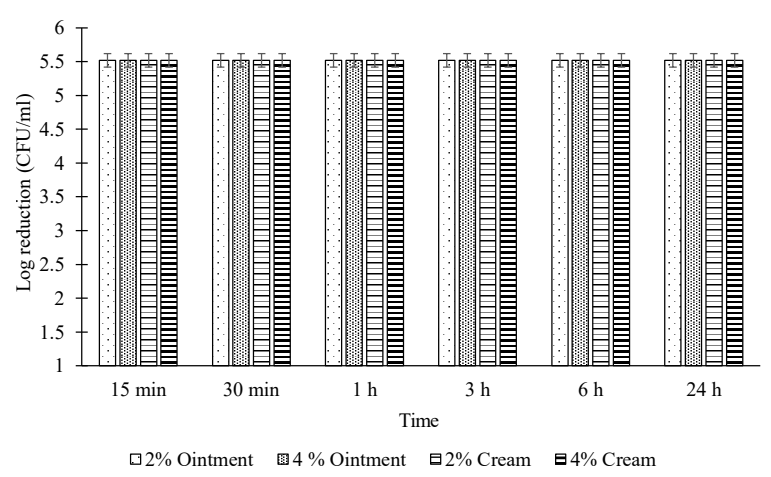

Fig. 2 The time-kill assay of clove essential oil ointment and cream against $M$. gallinae ATCC 90749 . Y-axis shows log reduction of viable fungal cells. Values represent the means of triplicate experiments with error bars (SD).

when used at concentrations of at least $2 \%$ of CO with 15 min of contact time. There are many studies supporting that $\mathrm{CO}$ in emulsion and nanoemulsion formulations has strong antifungal activity $[37,38]$. The ointment developed in our study was a hydrophilic emulsion of water and oil. The cream was an oil-in-water formulation, which makes it less greasy and easier to wash off with water compared to oleaginous creams or water-in-oil creams. The emulsion formulas are suitable for both oil-soluble and water-soluble active ingredients and allow the drugs to disperse and penetrate the skin. Also, the emulsion acts as a moisturizer that promotes drug contact to the skin for a longer time, which is useful for antimicrobial drugs that need extended contact time with microbes to improve their effectiveness $[39,40]$.

In conclusion, $\mathrm{CO}$ has strong antioxidant and antifungal activity, which results from its main constituent eugenol. When prepared as ointment and cream with $\mathrm{CO}$ at concentrations of $20-40 \mu \mathrm{l} / \mathrm{g}$ $(2-4 \% \mathrm{v} / \mathrm{w})$, the formulations were found to be active against $M$. gallinae, reducing the number of viable fungal cells by more than $99.99 \%$ within 15 min. Further studies should examine the stability, in vivo antifungal efficacy and potential for irritation of the formulations.

Acknowledgements: This work was supported by the Faculty of Veterinary Medicine, Khon Kaen University. The authors thank Dr. Glenn Borlace, Faculty of Pharmaceutical Sciences, Khon Kaen University for English language assistance.

\section{REFERENCES}

1. Grunder S, Mayser P, Redmann T, Kaleta EF (2005) 
Mycological examinations on the fungal flora of the chicken comb. Mycoses 48, 114-119.

2. Dhama K, Chakraborty S, Verma AK, Tiwari R, Barathidasan R, Kumar A, Singh SD (2013) Fun$\mathrm{gal} /$ mycotic diseases of poultry-diagnosis, treatment and control: a review. Pak J Biol Sci 6, 1626-1640.

3. Hubalek Z (2000) Keratinophilic fungi associated with free-living mammals and birds. Rev Iberoam Micol 17, 93-103.

4. Nweze EI (2011) Dermatophytoses in domesticated animals. Rev Inst Med Trop São Paulo 53, 94-99.

5. Miyasato H, Yamaguchi S, Taira K, Hosokawa A, Kayo S, Sano A, Uezato H, Takahashi K (2011) Tinea corporis caused by Microsporum gallinae: first clinical case in Japan. Int J Dermatol 38, 473-478.

6. Yamaguchi S (2019) Endangered zoonotic fungal species from chicken (Gallus gallus domestics). Med Mycol J 60, 45-49.

7. Bailey TA, Apo MM (2015) Pharmaceutical products commonly used in avian medicine. In: Samour J (ed) Avian Medicine, Elsevier, Missouri, pp 637-677.

8. Papich MG (2016) Saunders Handbook of Veterinary Drugs Small and Large Animal, Elsevier, Missouri.

9. Cortés-Rojas DF, de Souza CRF, Oliveira WP (2014) Clove (Syzygium aromaticum): a precious spice. Asian Pac J Trop Biomed 4, 90-96.

10. Park MJ, Gwak KS, Yang I, Choi WS, Jo HJ, Chang JW, Jeung EB, Choi IG (2007) Antifungal activities of the essential oils in Syzygium aromaticum (L.) Merr. Et Perry and Leptospermum petersonii Bailey and their constituents against various dermatophytes. $J$ Microbiol 45, 460-465.

11. Rana IS, Rana AS, Rajak RC (2011) Evaluation of antifungal activity in essential oil of the Syzygium aromaticum (L.) by extraction, purification and analysis of its main component eugenol. Braz J Microbiol 42, 1269-1277.

12. Aiemsaard J, Aiumlamai S, Taweechaisupapong S, Aromdee C, Khunkitti W (2010) Chemical composition, antioxidant activity and antibacterial action of eight essential oils against clinical isolates of mastitis pathogens. Int $J$ Esse Oil Ther 4, 37-43.

13. Amelia B, Saepudin E, Cahyana AH, Rahayu DU, Sulistyoningrum AS, Haib J (2017) GC-MS analysis of clove (Syzygium aromaticum) bud essential oil from Java and Manado. AIP Conf Proc 1862, ID 030082.

14. Lertsatitthanakorn $\mathrm{P}$, Taweechaisupapong S, Aromdee C, Khunkitti W (2006) In vitro bioactivities of essential oils used for acne control. Int $J$ Aromatherapy 16, 43-49.

15. Chamdit S, Siripermpool P (2012) Antimicrobial effect of clove and lemongrass oils against planktonic cells and biofilms of Staphylococcus aureus. Pharm Sci Asia 39, 28-36.

16. Pumnuan J, Insung A (2012) Effectiveness of essential oils from clove and cinnamon in controlling stored product mite, Suidasia pontifica Oudemans. KKU Sci J 40, 1205-1213.

17. Asawapattanakul T, Khunkitti W, Leesing R, Aiemsaard J (2013) The efficacy of essential oils against Malassezia pachydermatis isolated from canine otitis externa. Isan J Pharm Sci 9, 40-51.

18. Prashar A, Locke IC, Evans CS (2006) Cytotoxicity of clove (Syzygium aromaticum) oil and its major components to human skin cells. Cell Prolif 39, 241-248.

19. Alma $\mathrm{MH}$, Ertas M, Nitz S, Kollmannsberger $\mathrm{H}$ (2007) Chemical composition and content of essential oil from the bud of cultivated Turkish clove (Syzygium aromaticum L.). Bio Resour 2, 265-269.

20. Chaieb K, Hajlaoui H, Zmantar T, Kahla-Nakbi AB, Rouabhia M, Mahdouani K, Bakhrouf A (2007) The chemical composition and biological activity of clove essential oil, Eugenia caryophyllata (Syzigium aromaticum L. Myrtaceae): a short review. Phytother Res 21, 501-506.

21. Nurdjannah N, Bermawie N (2012) Clove oil. In: Peter KV (ed) Handbook of Herbs and Spices, Woodhead Publishing, Cambridge, pp 591-607.

22. Hemalatha R, Nivetha P, Mohanapriya C, Sharmila G, Muthukumaran C, Gopinath M (2016) Phytochemical composition, GC-MS analysis, in vitro antioxidant and antibacterial potential of clove flower bud (Eugenia caryophyllus) methanolic extract. J Food Sci Technol 53, 1189-1198.

23. Gülçin I, Elmastaş M, Aboul-Enein HY (2012) Antioxidant activity of clove oil: A powerful antioxidant source. Arab J Chem 5, 489-499.

24. Ghadermazi R, Keramat J, Goli SAH (2017) Antioxidant activity of clove (Eugenia caryophyllata Thunb), oregano (Oringanum vulgare L.) and sage (Salvia officinalis L.) essential oils in various model systems. Int Food Res $J$ 24, 1628-1635.

25. Nassar MI, Gaara AH, El-Ghorab AH, Farrag ARH, Shen H, Huq E, Mabry TJ (2007) Chemical constituents of clove (Syzygium aromaticum, Fam. Myrtaceae) and their antioxidant activity. Rev Latinoam Quim 35, 47-57.

26. Neveu V, Perez-Jiménez J, Vos F, Crespy V, du Chaffaut L, Mennen L, Knox C, Eisner R, et al (2010) Phenol-explorer: an online comprehensive database on polyphenol contents in foods. Database (Oxford) 2010, ID bap024.

27. Jirovetz L, Buchbauer G, Stoilova I, Stoyanova A, Krastanov A, Schmidt E (2006) Chemical composition and antioxidant properties of clove leaf essential oil. J Agric Food Chem 23, 6303-6307.

28. Gülçin I (2011) Antioxidant activity of eugenol: a structure-activity relationship study. $J$ Med Food 14, 975-985.

29. Salzano S, Checconi P, Hanschmann E, Lillig $\mathrm{CH}$, Bowler LD, Chan P, Vaudry D, Mengozzi M, et al (2014) Linkage of inflammation and oxidative stress via release of glutathionylated peroxiredoxin- 
2, which acts as a danger signal. Proc Natl Acad Sci USA 111, 12157-12162.

30. Hussain T, Tan B, Yin Y, Blachier F, Tossou MCB, Rahu N (2016) Oxidative stress and inflammation: What polyphenols can do for us? Oxid Med Cell Longev 2016, ID 7432797.

31. Sharma A, Sharma V, Kumawat TK, Seth R (2014) A review on antidermatophytic efficiency of plant essential oils. Int J Pure App Biosci 2, 265-278.

32. Abdeen E (2015) Antifungal activity of clove oil on dermatophytes and other fungi. Int $J$ Adv Res 3, 1299-1305.

33. Pinto SML, Sandoval LVH, Vargas LY (2019) In vitro susceptibility of Microsporum spp. and mammalian cells to Eugenia caryophyllus essential oil, eugenol and semisynthetic derivatives. Mycoses 62, 41-50.

34. Aiemsaard J, Punareewattana K (2017) Antifungal activities of essential oils of Syzygium aromaticum, Piper betle, and Ocimum sanctum against clinical isolates of canine dermatophytes. Sci Asia 43, 223-228.

35. Fernandez-Torres B, Carrillo AJ, MartÄśin E, Del Palacio A, Moore MK, Valverde A, Serrano M, Guarro $\mathrm{J}$ (2001) In vitro activities of 10 antifungal drugs against 508 dermatophyte strains. Antimicrob Agents Chemother 45, 2524-2528.

36. Devi KP, Nisha SA, Sakthivel R, Pandian SK (2010) Eugenol (an essential oil of clove) acts as an antibacterial agent against Salmonella Typhi by disrupting the cellular membrane. $J$ Ethnopharmacol 130 , 107-115.

37. Abd-Elsalam KA, Khokhlov AR (2015) Eugenol oil nanoemulsion: antifungal activity against Fusarium oxysporum f. sp. vasinfectum and phytotoxicity on cottonseeds. Appl Nanosci 5, 255-265.

38. Sharma A, Sharma NK, Srivastava A, Kataria A, Dubey S, Sharma S, Kundu B (2018) Clove and lemongrass oil based non-ionic nanoemulsion for suppressing the growth of plant pathogenic Fusarium oxysporum f. sp. lycopersici. Ind Crops Prod 123, 353-362.

39. Otto A, Plessis JD, Wiechers JW (2009) Formulation effects of topical emulsions on transdermal and dermal delivery. Int $J$ Cosmet Sci 31, 1-19.

40. Mohiuddin AK (2019) Skin care creams: formulation and use. Dermatol Clin Res 5, 238-271. 